NBER WORKING PAPER SERIES

DISTRIBUTIONAL IMPLICATIONS

OF IMPERFECT CAPITAL MARKETS

Joon Koo Lee

Working Paper No. 663

NATIONAL BUREAU OF ECONOMIC RESEARCH

1050 Massachusetts Avenue

Cambridge MA 02138

April 1981

This paper is based on parts of my $\mathrm{Ph} . \mathrm{D}$. dissertation. I wish to express my deep gratitude to Alan Blinder for his encouragement and valuable advice. I am also grateful to Harvey Rosen, Roger Gordon and Thad Mirer for their helpful suggestions. Financial support for this research was provided with a grant from the sloan Foundation to the Princeton University Economics Department. The research reported here is part of the NBER's research program in Labor Studies. Any opinions expressed are those of the author and not those of the National Bureau of Economic Research. 


\section{Distributional Implications of Imperfect Capital Markets}

\section{ABSTRACT}

The primary aim of this study is to analyze the impact of imperfections in capital markets on individuals' lifetime allocation plans and the resulting implications for income distribution. The model builds upon Samuelson's overlapping generation model with human capital and bequest motives playing central roles. The model developed here introduces a limit on the individual's ability to borrow. One of the most important consequences of this constraint is that human investment falls short of the level where its marginal return is equal to that of non-human investment. The comparative static results show that an individual who has been subject to the borrowing constraint would increase human investment unambiguously if he were allowed to borrow freely against future earnings. Discussions of the distributive implications of this result suggest that the elimination of the borrowing constraint has a potential of enhancing both intragenerational income equality and intergenerational mobility. The simulation results show that the elimination of the borrowing limit would bring about a significant improvement in income distribution without having an adverse effect on efficiency.

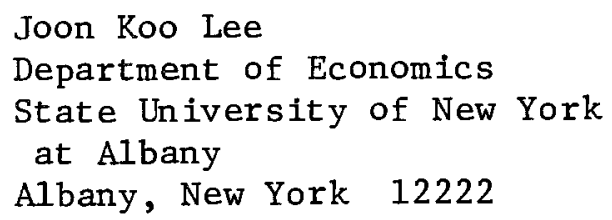


Although a satisfactory theory of the distribution of income is yet to come, significant progress has been made toward that goal by a series of attempts to establish general theories of income distribution by combining existing piecemeal theories into single synthetic models. One such example is Blinder's (1974) work which incorporates various elements of piecemeal theories. One of his main conclusions - is that inequality in income should not be ascribed to any single factor, but should be conceived as resulting from the optimizing behavion of individuals which can be affected by a number of factors. There is one potential cause of inequality, however, which evaded his attention totally: imperfect capital markets. Different income classes would be affected differentially by the imperfection in capital markets. Therefore, we might suspect that the present income distribution is influenced by the conditions of capital markets.

In a world of imperfect capital markets, the timing of the receipt of intergenerational wealth transfers plays an important role in one's lifetime allocation processes. As long as the capital markets are perfect, the assumption that bequest-at-death is the only channel of intergenerational wealth transfers, adopted in almost every study in the field as well as in Blinder's, does not pose any serious analytic problem even though a lange portion of such transfers is actually made in the form of inter vivos transfers. Ishikawa (1974) points out that, though in a world of perfect capital markets people are indifferent to the timing of wealth transfers, such neutrality no longer holds if there is some imperfection in capital markets. There are several studies confirining that poeple pass large sums of money to their descendants while the donors are still alive. In this study, therefore, both capital market imperfections and altennative channels of intergenerational wealth transfers are explicitly introduced.

The task of investigating the distributive implications of imperfect capital markets will be carried out using both theoretical models and simulation techniques. The use of numerical simulation in the study of the size distribution of income 
or wealth is rather a recent phenomenon. In his pioneering work, Pryor (1973) demonstrated that numerical simulation methods can be usefully employed in analyzing distributional impact of various social institutions. The potential of such methods was more convincingly demonstrated by a series of Blinder's works $(1974,1976)$.

his decomposition of inequality in income through numerical simulation added a new dimension to our knowledge on this subject. We should also mention important contributions along this line by orcutt et aI. (1976) whose microanalytic sinulation model proved to be a significant new tool for policy exploration in general as well as the analysis of income distribution. However, all these works were done under an explicit or implicit assumption of perfect capital markets, despite the fact that the existence of capital market imperfection might be a very important factor in understanding the present income distribution. The assumption of imperfect capital markets could provide a more realistic setting under which the distributive implications of various policy measures are analyzed.

Section I introduces the basic theoretical model. It is shown how our representative individual allocates resources over his or her life to maximize lifetime utility with given initial conditions. The main focus is on the individual's response to an easing of the borrowing constraint which he has been subject to. It is found that an increase in borrowing limit leads to an unambiguous increase in human investment of a constrained individual. Section II presents the setup of the simulation model. Section III reports the simulation results concerning the distributional impact of imperfect capital markets. The results under various alternative assumptions will be compared with the results obtained under the set of standard assumptions. Section IV concludes the study with some policy recommendations.

\section{The Model}

The present model is a version of the Samuelson (1958) overlapping generation model with human capital and bequest motives playing central roles. An individual model with human capled e. 
decision maker, assumed to live two periods of equal length, chooses at economic age zero an optimal plan of consumption, human investment, leisure and bequest to maximize his (or her) lifetime utility. I/ He is not "economically born" until after he is ready to choose and implement optimal plans of his own. He bears a child "asexully" during the first period, who begins his own economic life at the beginning of the next period. This rather simplistic assumption about the reproduction process is adopted here to avoid the complications arising from different regimes of mating behavior, quantity vs. quality of children, population growth, and so on.

He consumes and works throughout his economic life, i.e., in both periods. The basic asymmetry between the two periods is that he divides his time between work and human investment in the first period, while, in the second period, he chooses between work and leisure, instead of human investment. Bequest motives are also explicitly introduced in the model. Rather than stipulating that the only channel of intergenerational wealth transfer is through bequests-at-death, I assume that a substantial amount of non-human wealth is potentially transferable to the next generation while the agent is still alive. 2 /

T'o focus on agents' microeconomic optimization behavior, I assume away such macroeconomic concerns as growth, changes in the price level, unemployment and so on. I also assume at first that people have perfect foresight about events in the future; this assumption will be relaxed later on. It is also assumed that individual neither derives utility from the mere possession of human or non-human wealth; nor derives disutility from being in debt.

At economic age zero, a representative individual chooses an optimal lifetime plan with exogenously given wage rate $\left(w_{1}\right)$, non-kuman wealth $\left(A_{0}\right)$,.. and an .. inheritance (I) which he has not yet received but which he knows will be given at the beginning of the second period. In the first period, he decides the amount of time to be devoted to human capital accumulation $\left(m_{1}\right)$, own consurntion $\left(c_{1}\right)$, and inter vivos transfers $(T)$. The costs involved in human investment consist of 
foregone earnings $\left(w_{l} m_{l}\right)$ and direct costs. Since the latter accounts for only a small portion of total costs, it is assumed that foregone earnings are the only costs of accumulating human capital. The stock of ron-human capital at the end of the first period is then,

$$
A_{1}=\left\{1+\left(I-t_{2}\right) r\right\} A_{0}+\left(I-t_{1}\right) \omega_{1}\left(I-m_{1}\right)-C_{1}-\left(I+t_{3}\right) T
$$

where $\mathrm{r}$ : interest rate

$t_{1}:$ wage income tax rate

$t_{2}:$ interest income tax rate

$t_{3}:$ tax rate on inter vivos gifts.

Interest is assumed to accrue at the beginning of each period. It is also assumed that $A_{1}$ could be negative though not without limit. $3 /$ The borrowing limit can be a function of many factors. The most important of all must be his present earning ability. Therefore the capital market constraint is expressed as

$$
A_{1} \geqq-\left(I-t_{1}\right) q_{1}
$$

where $\mathrm{q}$ is a certain positive number.

His wage rate in the second period is given by

$$
w_{2}=w_{1} g\left(m_{1}\right)
$$

where $g\left(m_{1}\right)$ is strictly concave human capital production function. He is assumed not to do any human investment in the second period, while spending $\ell_{2}$ of his time as leisure. His stock of non-human wealth at the end of his life is given by,

$$
A_{2}=\left\{l+\left(1-t_{2}\right) r\right\}\left(A_{1}+I\right)+\left(I-t_{1}\right) w_{1} g\left(m_{1}\right)\left(1-\ell_{2}\right)-c_{2},
$$

which is assumed to be non-negative. 
One thing that deserves our attention is that $T$ and $\left(1-t_{4}\right) A_{2}$ of the current generation coincide with $A_{0}$ and $I$ of the next generation respectively where $t_{4}$ denotes the tax rate on bequests-at-death. 4 /

The objective furction which the agent tries to maximize consists of two parts: own utility and utility arising from the satisfaction of bequest motives. Therefore, it is written as

$$
U\left(C_{1}, C_{2}, l_{2}\right)+B\left\{T,\left(1-t_{4}\right) A_{2}\right\}
$$

where arguments are as defined in the previous section. The own utility part of the objective function, $U\left(C_{1}, C_{2}, \ell_{2}\right)$, is assumed to be monotone, strictly concave in $C_{1}, C_{2}$, and $l_{2}$, and twice differentiable. I also assume that this function is additively separable. This is a somewhat restrictive assumption, but concrete results cannot be derived without additive separability. The relationship between the two arguments in the $\mathrm{B}$ function is important. I assume that the true relationship lies somewhere between two polar cases: additive separability and perfect substitutability. In addition, I assume the B function is strictly concave.

We can observe the effects of the introduction of the capital market imperfection by comparing two systems of first-order conditions: one where the capital market constraint is not binding and the other with the constraint binding. Assuming for simplicity that all the endogenous variables have interior solutions, the following set of conditions will lead to an intertemporal optimum in case the capital market constraint is not binding.

$$
\begin{aligned}
& \frac{U_{1}}{U_{2}}=1+\left(1-t_{2}\right) r \\
& \frac{B_{1}}{B_{2}}=\left(1+t_{3}\right)\left(1-t_{4}\right)\left\{1+\left(1-t_{2}\right) r\right\} .
\end{aligned}
$$


The interpretation of these conditions are straightforward. The condition which must be satisfied for optimal human investment is given by,

$$
g^{\prime}\left(m_{1}\right)\left(1-l_{2}\right)=1+\left(1-t_{2}\right) r
$$

The left-hand side of this equation denotes the resulting increase in wage earnings in the sechad period when an extra dollar is invested in the accumulation of human capital, while the right-hand side denotes its opportunity cost. What this equation requires is simply that the costs and benefits of hunan investment should be equal at the margin.

In contrast, when the capital market constraint is strictly binding, intertemporal optimality conditions are changed to,

$$
\frac{U_{1}}{U_{2}}=1+\left(I-t_{2}\right) r+\frac{\mu}{\lambda}
$$

$$
\frac{B_{1}}{B_{2}}=\left(1+t_{3}\right)\left(1-t_{4}\right)\left\{1+\left(1-t_{2}\right) r+\frac{\mu}{\lambda}\right\},
$$

where $\mu$ and $\lambda$ denote the shadow price of the borrowing constraint and the marginal utility of terminal non-human wealth $\left(A_{2}\right)$ respectively, which are both strictly positive. Clearly, $\left\{1+\left(1-t_{2}\right) r+\frac{\mu}{\lambda}\right\}$ is bigger than $\left\{1+\left(1-t_{2}\right) r\right\}$. In the presence of the strictly binding capital market constraint, the effective rate of interest the agent faces is greater than the market rate of interest because the Former includes the shadow price of the borrowing constraint ( $\mu$ ). The capital market constraint acts as a distortionary factor, preventing him from allocating resources as well as he could under perfect capital markets. The optimal human investment condition is now changed to,

$$
g^{\prime}\left(m_{1}\right)\left(1-l_{2}\right)=1+\left(1-t_{2}\right) r+\frac{\mu}{\lambda} .
$$


He makes human investment up to the point where its marginal return is equal. to the effective rate of interest. Hence human investment will fall short of the unconstrained optimal level. i.e., where the marginal return is equal to market opportunity cost. There is possibly a link between thus distorted human investment. and the distribution of income. Since each individual is bound by the borrowing constraint to a different degree, the distribution of earnings in the presence of capital market imperfection must be different from what would have been in the absence of such imperfection. The existence of imperfections in capital markets could provide an important clue in understanding the causes of existing inequalities. The comparative static exercises in the next subsection will tell us what kind of distributional changes we can expect from eliminating such imperfection.

\section{Comparative Statics}

To focus on the effects the capital market constraint, I limit attention to the case where all of the six endogenous variables have interior solutions. The comparative static results for non-binding and strictly binding capital market constraint cases are summarized in Tables 1 and 2 . Of all the comparative static results, the ones of greatest interest are those involving the change in $q$, the proportion of potential wage earnings which determines the borrowing limit of the agent, for it is these results that suggest what kinds of distributional changes we can expect from easing the capital narket constraint. Though not adding directly to the stream of income, an increase in $q$ allows the agent to choose from among a wider range of alternatives. Our primary interest lies in its impact on the behavion of human investment. The finding is,

$$
\frac{d m_{1}}{d q}>0 \text { for people for whom the constraint is binding. }
$$

What this result means is clear: people are willing to invest more in human capital if they are able to bonrow more, for there are unexploited opportunities 
involved in human investment. Recall that an agent invests in human capital up to the point where the marginal increase in next periods income is equal to the opportunity cost of funds and that this oppontunity cost is highen than the going market rate of interest when the capital market constraint is binding:

$$
g^{\prime}\left(m_{1}\right)\left(1-l_{2}\right)=1+\left(1-t_{2}\right) r+\frac{\mu}{\lambda}
$$

An increase in $q$ arives down the shadow price of the capital market constraint $(\mu)$, thus lowering the value of the right-hand side of the equation. Unless an increase in $l_{2}$ absorbs all the decrease in the right-hand side, the agent will match this decrease by increasing human investment. The comparative static result we just obtained tells us that $\ell_{2}$ does not in fact rise this much.

An increase in the borrowing limit (q) has the potential of enhancing the economic well-being of consumens. The theorem of second best tells us that economic well-being improves if all distortions are uniformly decreased. There is only one source of distrotion in this model -- the existence of the capital market constraint which causes a divergence between the effective rate and the market rate of interest (by the amount of $\frac{\mu}{\lambda}$ ). A rise in q narrows the divergence by lowering $\mu$. This is clearly beneficial, according to the theorem of second best.

An increase in $q$ may also contribute to an equalization of the distribution of income or wealth. It is quite plausible that such a change is relatively more beneficial to the poor than to the rich. We have seen that those who have been constrained by the borrowing limit invariably respond to a rise in $q$ by increasing their human investments $\left(\mathrm{m}_{1}\right)$. Consequently their wage income will increase. This will benefit the rich as well as the poor, since a rich person is as likely as a poor one is to be constrained by the borrowing limit. However, the increase in wage income by an equal amount would mean more to a poor person, since it is a larger proportion of his income. The endowments of non-hunan capital would be the more important in deternining the individual's economic condition, the more the capital 
market constraint is binding. It is well known that the distribution of non-human capital is much more uneven than that of capital. As the relative importance of wage income among total income increases as a result of the rise in $q$, we can expect that the distribution of incone becones nore equal. Whether there will be an actual equalization of the distribution of income, on how much equalization will be realized if there is any is, of course, ultimately an empirical ratter. The simulation exercises in following sections will. shed some light on this point.

\section{Uncertain Returns from Human Investment}

Until now, it has been assumed that the agent has penfect foresight. It can be shown, however, that our most important result in the previous subsection,

$$
\frac{\mathrm{d} n}{\mathrm{dq}}>>0 \text {, }
$$

still holds true even in the setting of uncertainty. Among several sources of uncertainty in the context of the present model, I linit my attention to the case where the returns from human investments are uncertain.

The wage rate for the second period now depends on the time spent for human investment $\left(\mathrm{I}_{l}\right)$ and on the future state of the world $(\theta)$.

$$
w_{2}=w_{1} g\left(m_{1}, \theta\right)
$$

where $\theta$ is a random variable with a known distribution. As in the certainty case, I assume that $g_{1}>0$ and $g_{11}<0$. The derivative with respect to $\theta$ could have either sign; for concreteness, I assume $g_{2}>0.5 /$

The agent is assumed to know only the distribution of $\theta$ at the beginning of his life. His lifetime allocation plan should be based on this distribution. Once be knows the acturl wage rate in the market, he may find it desirable to modify the plan. Unlike the case of perfect foresight, therefore, his optimization process will consist of two stages. (See Appendix 2). 
File most of the comparative static rosults under uncertainty are ambiguous, the response of human investment to an increase in the borrowing limit (q) is unambiguously positive under plausible assumptions as shown in Appendix 2. It is thus proved that constrained individuals are willing to invest more in human capital if they are able to borrow more even though its future returns are uncertain. This finding can be used in addressing one of the important questions in the theory of human investment. There are several alternative explanations as to the observed gap between the marginal returns to huinain and non-human investments. Lazear (1977) attributes this tendency to the fact that the marginal utility of education is negative. According to Levhari and Weiss (1974), human investment may stop short of the level where its expected narginal return is equal to the marginal return on non-human capital, if the characteristics of the random variable satisfy certain conditions. 6/ What I have been trying to show is that a substantial part of such a tendency nay be attributed to the imperfection in capital markets. That $\frac{\mathrm{dm} l}{\mathrm{dq}}$ is positive even under the assumption of uncertain. returns from human investment strongly suggests that uncertainty alone cannot explain the whole thing. Lazear's assertion that the negative marginal utility of education is a key to the observed cleavage is hardly convincing. One commonily observed fact is that those who are very rich are likely to receive more education than the average person. Since they do not depend on wage earnings so much as the average person, they have no reason to receive more education if it gives them disutility. The implication is that they might derive positive utility from education. However, I can show that $\frac{\mathrm{dm}_{1}}{\mathrm{dq}}$ is still positive even if human investment $\left(m_{l}\right)$ enters the utility function as a disutility as Lazear's work suggests. 
II. Basic Setup of the Simulation Model

Objective Function

The objective function is assumed to take the form of an iso-elastic function:

$$
\begin{aligned}
U\left(c_{1},\right. & \left.c_{2}, \ell_{2}\right)+B\left(T,\left(1-t_{4}\right) A_{2}\right)=\frac{c_{1}^{1-\alpha}}{1-\alpha}+\frac{1}{1+\rho}\left(\frac{c^{1-\alpha}}{1-\alpha}+\tau \frac{l^{1-\gamma}}{1-\gamma}\right) \\
& +\frac{\sigma}{1-\beta}\left[1^{\varepsilon}+\left\{\left(1-t_{4}\right) \eta A_{2}\right\}^{\varepsilon}\right]^{1-\beta} \underline{I !}
\end{aligned}
$$

The utility-of-bequest part takes a slightly different form from the own utility pant because of the special relationship between $T$ and $A_{2}$. If the two arguments of the $B$ function are perfectly substitutable, then $\varepsilon$ should be equal to one. If, on the othor hand, they are additively separable, then $\beta$ should be equal to zero. The standard case assumes that the relationship is an intermediate one. Later on, the simulation results for the standard case will be compared with those for the two polar cases.

Creating a sample of Individuals

The simulation model starts with a sample of 200 individuals with given distributions of initial wage rates $\left(w_{l}\right)$, receipts of inter vivos transfers $\left(A_{0}\right)$ and inheritances (I) and a set of eight taste parameters, $\alpha, \rho, \gamma, \tau, \beta, \varepsilon, \sigma$, and $n$.

A. The Distribution of Initial Wage Rates $\left(w_{l}\right)$

The creation of the distribution of $\mathrm{w}_{1}$ was performed on the basis of actual micro-data frorn the Current Population Reports and Ohio State University's National Longitudinal Survey (NLS). The Consumer Income of the Current Population Reports has a break-down of average full-time wage earnings by age and the level of education. This can be used for computing the discounted sum of wage earnings during the second period for each education level, which in turn will be converted 
to the relevant wage rates by assuming that the average individual works only twothirds of total time available. $\frac{8 /}{-}$ As a result, the average wage rate of the lowest education group turns out to be 297.6 thousand dollars. This group of people can be identified with those who do not invest at all or only a very small amount in human capital formation.-9/ Therefore, the average initial wage rate, which is equal, by assumption, to the average second-period wage rate of those who do not invest human capital at all, should be very close to this figure. I assume it to be 280 thousand dollars.

The next step is to choose the adequatedispersion of the variable. The mean hourly wage rate of 10,128 respondents of NLS (full-time male workers of ages between 16 and 24 ) is $\$ 2.71$, while the standard deviation is \$1.11. Accordingly, the standard deviation of wage rates is set to 114.7 thousand dollars. The observation of the frequency distribution of young workers strongly suggests that a log-normal distribution, not a normal distribution, is a proper representation of the actual distribution. A sample of 200 initial wage rates is drawn from a log-normal distribution with the mean of 5.5572 and the standard deviation of $0.3939 .20 /$ The nighest wage rate in the sample is 711.4 thousand dollars for one period while the lowest is 93.0 thousand dollars. The Gini ratio for $\mathrm{w}_{1}$ turns out to be 0.211 .11 /

B. The Distribution of Intergenerational Wealth Transfers ( $A_{0}$ and $I$ )

of the two kinds of intergenenational transfers, some pieces of information have been gathered about bequests or inheritances received. However, nothing significant is known about inter vivos gifts. Therefore, the distribution of the theoretical variable $A_{0}$ in this study must be created completely out of guesswork. Since no updated and improved data on inheritances is known to me, I use the same data set as Blinder's (1974), that is, those collected by the Survey Research Center 
for creating the distribution of inheritances (I). $12 /$ The only significant modification is blowing up the magnitudes of inheritances to adjust for the change in purchasing power. $13 /$ The distribution of inheritances is created by taking an upper tail of a normal distribution with the mean of -20967.7 and the standard deviation of 40322.6 ; this makes the relative frequencies be $30.1 \%$ for those with positive inheritances and $3.9 \%$ for those with $\$ 50,000$ on more respectively. $14 /$

The distribution of inter vivos gifts is created in a similar way. An upper rail of a normal distribution with the mean of 4902.0 and the standard deviation of 19607.8 is taken so that the relative frequencies by $59.9 \%$ for those with positive inter vivos gifts and $10.0 \%$ for those with $\$ 30,000$ or more respectively. The correlation coefficient between $A_{0}$ and $I$ is expected to be very high. This is set to 0.95 arbitrarily.

However, one further modification should be made to the products of the random number generator. The highest inheritance produced is merely $\$ 108,610$, far from the magnitudewhich we normally expect to be the inheritance of a millionaire. To make the created sample look more realistic, I multiply the seven highest inheritances by numers from 2 to 9 . And inter vivos gifts matched with them are also multiplied by the same numbers respectively. The Gini coefficients of the variables $A_{0}$ and I turn out to be 0.805 and 0.913 respectively. Intergenerational. wealth transfers are set to be distributed quite unequally. The correlation coefficient between $w_{0}$ and $A_{0}$ as well as between $w_{0}$ and $I$ is set to by 0.12 using the estimate of Blinder (1976). 
The I) istribution of Taste Parameters

Of eight taste parameters which could conceivably vary across individuals, I allow only foun variables to vary keeping the rest four invariant for the whole sample population. The critexion of such a division is not the impontance of variables, but sheer convenience. The four variables which will be held invariant across individuals are:

(i) $\alpha$, the speed at which the marginal utility of consumption declines as consumption increases, is set to 1.5 .

(i.i) $\gamma$, the speed at which the marginal utility of leisure declinos as consumption of leisure increases, is also set to 1.5 .

(iii) $\varepsilon$ and $\beta$, which, as a group, determine the relationship between the two arguments in the $B$ function and the speed at which the marginal utility of intergenerational wealth transfors declines as their quantities increase are set to 0.7 and 0.9 respectively.

The choice of 1.5 for $\alpha$ is consistent with most of other studies on the subject. 15/. The parameter $\gamma$ is set equal to $\alpha$ for the standard case since there is no conclusive evidence about the income elasticity of leisure consumption. $16 /$ But a higher and a lower value of $\gamma$ will also be tried to see the impact of different income elasticities of leisure consunption on the distribution of income. The choice of the values for $\varepsilon$ and $\beta$ is made to satisfy the following two requirements. First, the income elasticity of intergenerational wealth transfers should be higher than that of consumption or leisure choice. Second, the average ratio of inter vivos gifts to bequests-at-death individuals choose should lie in some reasonable region. After numerous iteration, it was found out that the choice of 0.7 for $\varepsilon$ and 0.9 for $\beta$ satisfies the above requirements fairly well.

All the parameters which are allowed to vary across individuals are assumed to have normal distributions.

(1) The mean value of $\rho$, the parameter which represents the subjective 
rate of time discounting, is chosen to be 0.33 , corresponding to an annual subjective discount rate of $1.0 \%$. This in turn will lead to the mean value of 0.75 for $\frac{1}{1+\rho}$. The standard deviation for $\frac{1}{1+p}$ is arbitrarily set to 0.2 to allow sizable dispersion in time preferences.

(2) The mean value of $\tau$, the parameter which represents the subject's preforence of leisure in relation to other consumption goods, is set equal to 0.015 so that the average person's choice of leisure be.0.7 of his available time. The standand deviation of $\tau$ is set to be one-thind of the mean.

(3) The choice of the mean value of $\sigma$, the parameter representing the relative preference for intergenenational wealth transfers, is made to let the average amount of intergenenational wealth transfers to the next generation net of tax be approximately equal to the average amount individuals receive from the previous generation. After some itenations, the value of 0.001 is chosen. The standard deviation of $\sigma$ is arbitrarily set to 0.0003 .

(4) The last taste parameter to be determined is $n$. This paramten reflects an individual's subjective preference between the two channels of intengenenational wealth transfers; inter vivos gifts and bequests-at-death. Since the bequest-at-death is made one period after the inter vivos gift, the rate of interest on the subjective rate of time discount can be used as a guide to choose the mean value of $n$. People might feel that inter vivos gifts are relatively more valuable to their clescendants in the world of imperfect capital markets. Hence the mean value of $\eta$ is set to 0.4 , which is slightly smallen than $\frac{1}{1+r}$. The standard deviation of $n$ is again arbitrarily set to 0.1 .

A question may arise as to the possible correlation between taste paramters 
among themselves or between taste parameters, wage rates, or inherited wealth. Since Blinder (1974) has dealt with the problen already, I will stick to the case where no correlation exists between them. 17 /

It has been assuned that the human capital production function be strictly concave. In actuality, however, the existing data suggest that the function is rather linear or even convex.18/ As a compromise, a function with very small concavity is chosen. The human capital production function is assumed to be given by,

$$
g\left(m_{1}\right)=-2.3 m_{1}^{2}+5.3 m_{1}+c .19 /
$$

This function is chosen on the basis of NLS data mentioned earlier.

Even though the present model is basically one of imperfect capital markets, a single rate of interest is assuned for borrowing and lending. This is also used for discounting future income streams. Most of the estimates of the long-term real rate of interest range from $3 \%$ to $8 \%$ per annum. But I feel they are rather on the higher side. A rate of $3 \%$ per annum will be used in this study. Hence the rate of interest for one period ( 30 years compounded ammally) is assumed to be $143 \%$.

Proportional rates are assumed for various taxes here for simplicity. Since there is no conclusive evidence on the incidence of tax burdens under the present U.S. tax system, the proportional rate of the personal income tax calculated from the data in the 1979 edition of Statistics of Income will be used as the rates of the wage income tax $\left(t_{1}\right)$ and the interest income tax $\left(t_{2}\right)$. The ratio of personal income tax receipts to income subject to tax was 0.21 on 1976 returns.

The proportional rate of tax on the bequest-at-death $\left(t_{4}\right)$ is calculated from the data of estate tax returns as reported in the 1979 edition of Statistics of Income, which is found out to be $12 \%$. The rate of tax on inter vivos gifts $\left(t_{3}\right)$, however, cannot be calculated in such a manner, since there is no exact real world counterpart of such a tax. Due to many deductible items as well as loopholes 
involved in such kinds of transfers, the effective rate of tax is supposedy very low. I assume it to be $5 \%$, which is much lowor than $t_{4}$.

III. Distributional Impact of Capital Market Imperfection

In this section, the results of simlation exercises as to the distributional impacts of capital market imperfection under various assumptions will be presented. The alternative assumption which will replace the standard ones are sumarized in the following.

(i) The shape of the uitlity of bequest (B) function.

The cases of perfect substitutability and additive separability will be considered.

(ii) Different income elasticities of leisure consumption. The standard case assumes that the value of $\gamma$ is equal to that of $\alpha$.

The cases with a higher and a lower elasticity of marginal utility of leisure will be considered.

(iii) Different distributions of inter vivos gifts $\left(A_{0}\right)$.

As pointed out earlier, our information on this kind of transfer is almost non-existent. The standard case assumes that $60 \%$ of .... people receive positive inter vivos gifts while $10 \%$ of people receive more than 30 thousand dollars. The impact of more on less skewed initial distributions of $A_{0}$ will be studied.

\section{The Standard case}

My starting point is the case where each individual is able to borrow onetenti of his current wage rate (i.e., $q=0.1$ ), the utility-of-bequest function takes the intermediate form, and all the paraneters have the value stated in the previous sections. The distribution of lifetime potential incone (LPI) resultirg from the simulation is shown in Table 3 . While the level of utility itself should be the criterion by which one's economic well-being is measured, 
intarent difficulties involved in cardinalization of utility makes it inevitable to substitute it with a proxy variable in studying distributive problems. Hence, lifetime potential incone which includes the imputed value of consumed leisure is adopted as a measure of one's economic well-being in this study. More concretely, the lifetime potential income is defined as, (14) $\operatorname{LFI}=C_{1}+\mathrm{r}+\frac{1}{1+\left(1-\mathrm{t}_{2}\right) r}\left\{c_{2}+w_{2} l_{2}+\left(1-t_{4}\right) A_{2}\right\} \underbrace{201}$ The first thing to note is that the lifetime income is defined by net consumption. The other point is that one's own wage rate is used in calculating inputed value of leisure consumption. As shown in Table 3 , the Gini ratio for LPI turns out to be 0.2543. And the average person sperds 0.285 of his total time available ( 8.55 years) during the first period in human capital accumulation.

When every individual is allowed to borrow freely against his future income, it is observed that the average human investment drastically increases from 0.285 to 0.539 . As the result, a majority of people now have higher wage rates for the second period. This increase in the relative importance of wage earuings reduces the Gini ratio from 0.2543 to 0.2452 . The reduction in the Gini ratio by $3.6 \%$ does not look very great, but the improvement in the distribution of lifetine incomes, not short-run monetary incomes, of this magnitude is hardly insignificant. The Gini ratio for the second period income (SPI) alone is observed to decrease by as much as $8.5 \%$ (From 0.2254 to 0.2062). $2 \mathrm{~V}$ Note that this second period incone is the closest counterpart of the annual monetary income which is the most widely used measure of economic well-being. In addition to contributing to the equalization of income distribution, the increase in human investment can possibly raise the absolute level of national income. The simulation results show that the gain in national income due to the increase in human investment amounts to 15,098 thousand dollars, or $20.4 \%$ of total income, when evaluated at the current wage rates. 22 /

As is well known, the comparison of two Gini ratios is meaningful only if the two Lorenz curves lying behind them do not intersect each other. 23 / Fortunately, 
the two Lorenz curves, one with the capital market constraint and the other without it, do not intersect. (See Table if)

\section{Alternative Assumptions on the shape of the B Function}

The simulation results show that changes in the assumption about the shape of the $B$ function does not change the picture much. It is expected that the equalization due to the elimination of capital market imperfections:

will be less if. the substitutability between the two arguments of the $B$ function is greater. This is because easier substitution of one type of intergenerational transfer with the othen type of tarnsfer could lessen the degree to which the capital market constraint binds the subject. This expectation is supported by simulation results only in part. That is, while the simulation results in the, case of perfect substitutability turn out to be consistent with this expectation; those in case of additive separability show the opposite tendency. The degree of improvanent in the distribution of lifetime potential incone (IPI) when the capital market constraint is eliminated falls from $3.6 \%$ of the standard case to $3.2 \%$ if the two arguments of the $B$ function are perfectly substitutable. Contrary to the expectation, the additive separable case also leads to a slight fall in the degree of improvement, though the change is very small. It turns out that the distribution of LPI improves by $3.5 \%$ when the $B$ function is additively separable, as compared to $3.6 \%$ in the standard case (see Table 5).

Ow conclusion from the above discussion might be that the change in the assumption about the shape of the B function does not modify the results of the standard case very much. Note, however, such a conclusion should be confined to the case of single-generation experiment. When it comes to the experiment with multigeneration, we might reach a quite different conclusion. 24 In view of the high sensitivity of individuals' behavion concerning bequest motives to differing 
assumptions on the relations between two kinds of intergenerational weilth transfers and the critical roles that such intergenerational wealth transfers play in individuals' lifetime allocation processes, it is very plasible that the distributive pictures aften several generations would be quite different from each other depending upon the specific assumption chosen.

\section{Different Elasticities of the Manginal Utility of Leisure}

The standard case assumes that the elasticity of the marginal utility of leisure, $\gamma$, is equal to 1.5. However, the estimates of the income elasticity of labor supply from which a value for the paraneter $\gamma$ can be inferred are very much varied. Therefore it will be useful to try different values for $\gamma$ and see how the results differ from those of the standard case.

It is shown in the Appendix how to transform an estimate of the income elasticity of labor supply into a value for the parameter $\gamma$. According to the formula, a value of 1.5 for $\gamma$ is consistent with the income elasticity of labor supply having a value of -0.04 .25 since most of the estimates of income elasticity for male workers are concentrated in the region 0.00 to -0.16 , both higher and lower values for $\gamma$ should be tried. The two values chosen are 0.5 and 2.5 . When $\gamma$ is set equal to 0.5 rather than 1.5 , the elasticity of the marginal utility is lower, so that people spend a langer portion of increased unearned income on leisure than they would do in the standard case. The opposite will hold true when $\gamma$ is set equal to 2.5 .

It is expected that the lower the value for the parameter $\gamma$ is, the greater the impact of the elimination of capital market imperfection. When $\gamma$ has a low value, i.e., leisure has more of the characteristic of a luxury good, there will be a largc variance in leisure consumption anong individuals. Since the rich are expected to consume large amouits of leisure, they have little incentive to increase human investment even though they are allowed to borrow without limit. On the other hand, 
the poon will invest heavily in the formation of human capital stock which is to be used intensively, if they are able to borrow without limit against future eannings. This asymnetry, which gets larger as the value for $\gamma$ becomes lower, may lead to the difference stated above.

As can be seen in Table 5, the simulation results suppont this expectation. When the $\gamma$ is set equal to 0.5 , the degree of reduction in the Gini ratio for LPI when borrowing constraint is eliminated anounts to $5.0 \%$, which is significantly larger than $3.6 \%$ in the standard case. When $\gamma$ is set equal to 2.5 , it falls to 2.9\%. Note also that the distributions of SPI vary in consistence with our expectation. One interesting observation is that the increase in human investment gets greater as the value for $\gamma$ becomes lower.

Different Distributions of inter vivos Gifts

The standard case assumes that $60 \%$ of individuals in the sample population receive positive inter vivos gifts $\left(\mathrm{A}_{0}\right)$ from their parents while $10 \%$ of people receive 30 thousand dollars or more of such gifts. As mentioned before, these figures come completely out of guesswork. If the initial distribution of $\mathrm{A}_{0}$ were more skewed, then probably more people would be constrained by the borrowing limit, and so the impact of the elimination of capital market imperfection would be greater. The simulation results confirm this prediction. If a more skewed distribution of $\mathrm{A}_{0}$ ( $45 \%$ above zero and $6 \% 30$ thousand dollars or more) is taken, the Gini ratio of the distribution of LPI falls by $3.8 \%$ when the borrowing limit is elipinated as compared to $3.6 \%$ of the standard case. $\frac{26 / 4}{}$ A less skewed distribution of $A_{0}(75 \%$ above zero and $15 \% 30$ thousand dollars or more) is observed to result in less reduction in the Gini ratio than in the standard case. $\frac{27 /}{\text { The }}$ other simulation results are summarized in Table 5 . Note that the elinination of capital market imperfection could still be effective in improving income distribution 
even under a rather extreme assumption that three quarters of people receive positive inter vivos gifts.

IV. Conclusions and Policy Irrplications

The andyses in previous sections suggest that at least a part of the existing inequality in incone can be attributable to the imperfection in capital mankets. This in turn suggests that the income distribution will become more equal if such imperfections are eliminated. The government can achieve a significant gain in its effort to equalize income distribution either by furnishing more generous loans for human investment purposes directly or encouraging the private sector to take nore liberal lending policies toward this kind of loan requests.

Easing the grip of the capital market constraint, as a redistributive policy measure, seems to have several advantages over other redistributive measures, existing on proposed. The first one is that such a measure could achicve redistribution without hurting anyone in society in absolute terms. Those who have been constrained by the borrowing limit would be unambiguously better off, while those who have not been would be at least as well off as before. The nature of redistribution is not giving the money taken from the rich to the poor, but making the poor relatively better off by allowing them to exploit unused opportunities of human investnent. Therefore, the society can enjoy a bigger economic pie, as well as more equal shares.

The second advantage is that one need not bother to sort out only those who deserve public help as other redistributive measures require to do, since everyone. who is willing to exploit the unused opportunities and is ready to repay in the next period is free to borrow under this system. And finally, this measure would lead to greater intergenerational mobility by providing children from poor families with the means to exploit the opportunities of human investment to their fullest. This measure would let society 
approach the principle of equal opportunity a little more closely.

Here one question might arise. If there actually exists such unexploited opportunities in the economy, then why has the private sector failed to exploit them? Or, in other words, what puts the government in a better position to do the job? Supposing that the private sector acts rationally, if such opportunities actually existed, it-would make the best use of them, even without the government intervention. Probably, one of the most important reasons for the existence of the capital market imperfection is moral hazard. Bankers are reluctant to lend money against future earnings, since the default risks involved in such lending practices are too high for them. The difficulties bankers have in enforcing the repayment of unsecured loans are related to high costs of legal actions, both in terms of time and money, in case they are necessary. Loans of such a kind as proposed in this study will give bankers more headaches than profits, since the number of accounts they have to take care of is astronomical while the size of, and therefore the profit from, each account is relatively small.

Now the question is narrowed to this: Is the welfare gain from government intervention lange enough to offset the efficiency loss which might accompany such government intervention? Even though a definite answer cannot be given on a priori grounds, there seems to be good reasons to think that the answer is in the positive. As pointed out in previous sections, the welfare gains expected from the elimination of such imperfection are two-fold. First, the elimination of the distortionary factor in one's intertemporal optimization process will lead to an efficiency gain. second, the distribution of income will be favorably affected by such a change. It is very implausible that the possible efficiency loss due to the public assumption of a role which could have been best served by the private sector dominates the sum of the two. Moreover, such an efficiency loss can be minimized if the government does not directly intervene in financial markets but just 
provides appropriate environment for improved functioning of the mankets. The government's guarantee for such loans might be enough to persuade private bankers into utilizing such unexploited oppontunities. 
APPENDIX 1. Conversion of the Incone Elasticity of Labor Supply into the Elasticity of Marginal Utility of Leisure.

Suppose that the observed value of the income elasticity of labor supply is consistent with the solution of the following instantaneous utility maxinization problem.

(A. I)

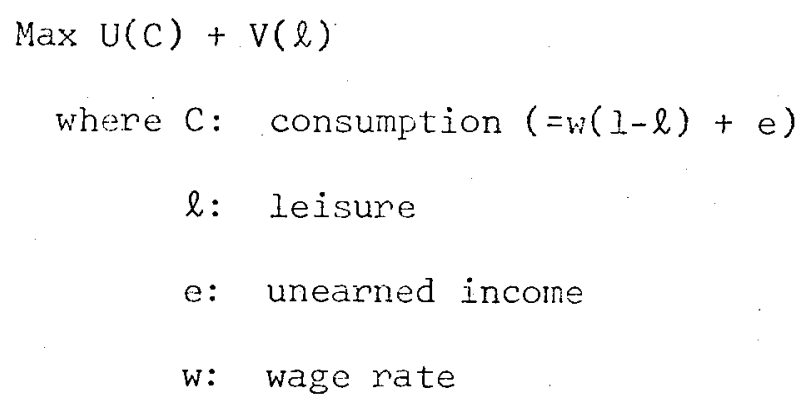

In the context of the present model, $C$ includes intergenerational wealth transfers as well as ordinary consumption. The first order condition for an optimum is,

$$
V^{\prime}-w U^{\prime}=0
$$

Totally differentiating Eq. (A.2), we have

$$
\text { (A.3) } \quad \frac{\mathrm{d} \ell}{\mathrm{de}}=\frac{\mathrm{w} U^{\prime \prime}}{\mathrm{V}^{\prime \prime}+\mathrm{w}^{2} \mathrm{U}^{\prime \prime}}=\frac{1}{\frac{\mathrm{U}^{\prime}}{\mathrm{U}^{\prime \prime}} \frac{\mathrm{V}^{\prime \prime}}{V^{\prime}}+\mathrm{w}}
$$

The income elasticity of labor supply $(\xi)$ is given by,

$$
\text { (A.4) } \quad \xi=-\frac{e}{I-\ell} \frac{d \ell}{d e}=-\frac{e}{I-\ell} \cdot \frac{I}{\frac{U^{\prime}}{U^{\prime \prime}} \frac{V^{\prime \prime}}{V^{\prime}}+w}
$$

Since the function $U$ and $V$ are given by

$$
U=\frac{C^{1-\alpha}}{I-\alpha} \text { and } V=\frac{\ell^{1-\gamma}}{1-\gamma}
$$

we have
(A.5)
$v^{\prime}=e^{-\gamma}$ 
and

$$
(A .6) \quad V^{\prime \prime}=-\gamma e^{-\gamma-1}
$$

Dividing Eq. (A.5) by Eq. (A.6), we have,

$$
\frac{V^{\prime}}{V^{\prime \prime}}=-\frac{\ell}{\gamma}
$$

or

$$
\gamma=-l \frac{\dot{V^{\prime \prime}}}{\mathrm{V}^{\prime}}
$$

From Eqs. (A.4) and (A.7), the following formula which relates $\xi$ to $\gamma$ can be derived.

$$
\begin{aligned}
\gamma & =-\ell \frac{V^{\prime \prime}}{V^{\prime}}=\ell \frac{U^{\prime \prime}}{U^{\prime}}\left(\frac{e}{\xi(1-\ell)}+w\right) \\
& =-\frac{\alpha \ell}{c}\left(\frac{e}{\xi(1-\ell)}+w\right) \\
& =-\frac{a l}{(1-\ell)+\frac{e}{w}}\left(\frac{\frac{e}{w}}{\xi(1-\ell)}+1\right)
\end{aligned}
$$$$
\text { (A.8) }
$$

Taking an average value of $\ell$ to be 0.3 and assuming that the ratio of unearned income to the wage rate $\left(\frac{e}{w}\right)$ to be 0.1 , we can simplify Eq. (A.8),

$$
\text { (A.8') } \quad \gamma=-\frac{0.3}{0.8} \alpha\left(\frac{0.1}{0.7 \cdot \xi}+1\right)
$$

Remembering that we set $\alpha$ equal to 1.5 , we can futher simplify the formula,

$$
\text { (A. } \text { (") }^{\prime \prime} \quad \gamma=-0.0804 \cdot \frac{1}{\xi}-0.5625
$$


APPEHDIX 2: Optimization Process When the Returns from Human Investment Are uncertain.

When the returns from human investment are uncertain, an individual's Iifetime optinization process consists of two stages. First, he decides how he shall determine the optimal $c_{2}, l_{2}$ and $A_{2}$ once all exogenous variables, finst-period variables, and the random varjable, $\theta$, are realized. This amounts to expressing the optimal $C_{2}, \ell_{2}$ and $A_{2}$ as functions of those variables. This task can be done by maximizing

$$
U\left(C_{1}, C_{2}, l_{2}\right)+B\left(T, A_{2}\right)
$$

with respect to $\mathrm{C}_{2}, \mathrm{I}_{2}$ and $\mathrm{A}_{2}$ subject to relevant constraints. The next stage is to maximize the expected utility using the results obtained above.

$$
\underset{C_{1}, M_{1}, T}{\operatorname{Maximize}} \quad \mathrm{E}\left[\mathrm{U}\left\{\mathrm{C}_{1}, \mathrm{C}_{2}(\cdot), \ell_{2}(\cdot)\right\}+\mathrm{B}\left\{\mathrm{T}, \mathrm{A}_{2}(\cdot)\right\}\right]
$$

again subject to relevant constraints.

The derivative which we are most interested in, $\frac{d m}{d q}$, can be figured out from the first onder conditions for the second stage optimization presented below:

$$
\begin{gathered}
E\left[U_{1}+\left(U_{2}-B_{2}\right) \frac{\partial C_{2}}{\partial C_{1}}-B_{1}+\left\{U_{3}-w_{1} g\left(m_{1}, \theta\right)\right\} \frac{\partial l_{2}}{\partial C_{1}}\right]=0 \\
E\left[\left(U_{2}-B_{2}\right) \frac{\partial C_{2}}{\partial m_{1}}+\left\{U_{3}-w_{1} g\left(m_{1}, \theta\right)\right\} \frac{\partial l_{2}}{\partial m_{1}}-w_{1} B_{1}+w_{1} g_{1}\left\{l-l_{2}(\cdot)\right\}_{2}\right]=0 .
\end{gathered}
$$

We have this very complicated expression for the response of human investment $\left(m_{1}\right)$ to an increase in the borrowing limit $(q)$ under uncertainty: 


$$
\begin{aligned}
& \left.\frac{\mathrm{dn}}{\mathrm{dq}}\right|_{\mathrm{u}}=\frac{1}{\mid \mathrm{F} T}\left(\mathrm { E } \left[-\frac{1}{|\mathrm{D}|}\left\{\mathrm{U}_{11} \mid \mathrm{D}+\mathrm{B}_{11} \mathrm{U}_{22} \mathrm{U}_{33}+\right.\right.\right. \\
& \left.\left.\left(\left(w_{1} g\right)^{2} U_{22}+U_{33}\right)\left(B_{11} B_{22}-B_{12} B_{21}\right)\right\}\right] \cdot E\left\{\frac{1}{|D|}\right. \\
& \left.B_{1} w_{1} U_{22}\left(B_{21}-(I+r) B_{22}\right)\left(w_{1} g B_{2}-h_{2} U_{33}\right)\right\} \\
& -E\left[\frac{l}{|D|}\left\{g_{1} B_{2 L} \mathrm{U}_{22}\left(w_{1} \mathrm{gB}_{2}-\mathrm{h}_{2} \mathrm{U}_{33}\right)-\mathrm{U}_{11}|\mathrm{D}|\right\}\right] \text {. } \\
& E\left[\frac { 1 } { | D | } \left\{w_{1}\left(\left(w_{2} g\right)^{2} U_{22}+U_{33}\right)\left(B_{11} B_{22}-B_{12}{ }_{21}\right)\right.\right. \\
& \left.\left.\left.+w_{1} U_{22} U_{33}\left(B_{11}-(I+r) B_{12}\right)\right\}\right]\right)
\end{aligned}
$$

where $|D|$ and $|F|$ denote the deteminants of endogenous matrices for the first and the second stages of optimization process respectively. Both of them are positive under plausible assumptions. ${ }^{29 /}$ since every term in the expression is positive, we can establish that $\left.\frac{\mathrm{d} n}{\mathrm{dq}}\right|_{u}$ is unambiguously positive. 
Table 1

Summany of Comparative Static Results--Interion Solutions Eor Endogenous Variables and Binding Capital Market Constraints

\begin{tabular}{|c|c|c|c|c|c|c|}
\hline & $\mathrm{dc}_{1}$ & $\mathrm{dc}_{2}$ & $\mathrm{dm}_{1}$ & $\mathrm{dl}_{2}$ & $\mathrm{dT}$ & $\mathrm{dA}_{2}$ \\
\hline $\mathrm{dA} \mathrm{A}_{0}$ & + & + & - & + & + & + \\
\hline $\mathrm{d} I$ & + & + & - & + & + & + \\
\hline $\mathrm{dw}_{1}$ & + & + & $?$ & $?$ & + & + \\
\hline $\mathrm{dr}$ & $?$ & $?$ & $-*$ & $+*$ & $?$ & $?$ \\
\hline $\mathrm{dt}_{1}$ & - & - & $?$ & $?$ & - & - \\
\hline $\mathrm{dt}_{2}$ & $?$ & $?$ & $+*$ & $-*$ & $?$ & $?$ \\
\hline $\mathrm{dt}_{3}$ & $?$ & $?$ & $?$ & $?$ & - & $?$ \\
\hline $\mathrm{dt}_{4}$ & + & + & - & + & + & - \\
\hline
\end{tabular}

*Conditional on the assumption that $\left\{1+\left(1-t_{2}\right) r\right\} A_{0}+A_{1}+I \geqq 0$. 
Summany of Companative Static Results--Interior Solutions for Eindogenous Variables and Binding Capital Vanket Constraints

\begin{tabular}{|c|c|c|c|c|c|c|}
\hline & $\mathrm{dC}_{1}$ & $\mathrm{dC}_{2}$ & $\mathrm{dm}_{1}$ & $d I_{2}$ & $\mathrm{dT}$ & $\mathrm{dA}_{2}$ \\
\hline $\mathrm{dq}$ & + & $?$ & + & $?$ & + & ? \\
\hline $\mathrm{dA}_{0}$ & + & + & ? & ? & + & ? \\
\hline $\mathrm{d} I$ & + & + & - & $?$ & ? & $?$ \\
\hline$d w_{1}$ & + & $?$ & $?$ & $?$ & $?$ & $?$ \\
\hline $\mathrm{dr}$ & $+*$ & ? & $?$ & $?$ & $+*$ & $?$ \\
\hline$d t_{1}$ & - & $?$ & $?$ & ? & $?$ & $?$ \\
\hline$d t_{2}$ & $-*$ & $?$ & $?$ & ? & $\therefore$ & $?$ \\
\hline$d t_{3}$ & $?$ & ? & ? & $?$ & - & ? \\
\hline$d t_{4}$ & ? & ? & -7 & + & + & - \\
\hline
\end{tabular}

*Conditional on the assumption that $\left\{1+\left(1-t_{2}\right) r\right\}_{0}+A_{1}+I \geq 0$. 
Table 3

Impact of the Elimination of Borrowing Constraint: Standard Case

\begin{tabular}{|l|c|c|c|}
\hline & $\begin{array}{c}\text { With } \\
\text { Constraint }\end{array}$ & $\begin{array}{c}\text { Without } \\
\text { Constraint }\end{array}$ & $\begin{array}{c}\text { Percent } \\
\text { Change }\end{array}$ \\
\hline Gini Ratio for LPI & 0.2543 & 0.2462 & $-3.6 \%$ \\
\hline Gini Ratio for SPI & 0.2254 & 0.2062 & $-8.5 \%$ \\
\hline $\begin{array}{l}\text { Average Human } \\
\text { Investment }\end{array}$ & 0.285 & 0.539 & $+89.1 \%$ \\
\hline $\begin{array}{l}\text { Ind Period Total } \\
\text { Income (In } \\
\text { Thousand Dollars) }\end{array}$ & 74173 & 89271 & $+20.4 \%$ \\
\hline
\end{tabular}


Table 4

Distribution of Incomes With and Without the Borrowing constraint: Standard Case

\begin{tabular}{|c|c|c|c|c|}
\hline \multirow{3}{*}{ Population Group } & \multicolumn{4}{|c|}{ Share in Total (\%) } \\
\hline & \multicolumn{2}{|c|}{ Lifetime Potential Income } & \multicolumn{2}{|c|}{ Second Period Income } \\
\hline & With & Without & With & Without \\
\hline Lowest $10 \%$ & 4.49 & 4.60 & 4.60 & 4.88 \\
\hline Secoind $10 \%$ & 5.84 & 5.92 & 6.08 & 6.31 \\
\hline Third $10 \%$ & 6.67 & 6.77 & 6.91 & 7.11 \\
\hline Fourth $10 \%$ & 7.57 & 7.68 & 7.88 & 8.28 \\
\hline Fifth $10 \%$ & 8.67 & 8.87 & 8.94 & 9.09 \\
\hline Sixth $10 \%$ & 9.45 & 9.50 & 9.80 & 10.0 .1 \\
\hline Seventh $20 \%$ & 10.07 & 10.09 & 10.64 & 10.68 \\
\hline Eighth $10 \%$ & 11.19 & 11.19 & 11.87 & 11.77 \\
\hline Ninth $10 \%$ & 12.98 & .13 .07 & 13.95 & 13.70 \\
\hline Highest $10 \%$ & 23.07 & 22.31 & 19.33 & 18.17 \\
\hline (Top 2.5\%) & 14.94 & 14.28 & 6.23 & 5.72 \\
\hline (Top $1 \%)$ & 5.17 & 4.82 & 2.80 & 2.51 \\
\hline
\end{tabular}


Table 5

Impact of the Elimination of Borrowing Constraint Under Various Alternative Assumptions

\begin{tabular}{|c|c|c|c|c|c|c|c|c|c|}
\hline \multirow{2}{*}{ Assumptions } & \multicolumn{3}{|c|}{ Gini Ratio for LPI } & \multicolumn{3}{|c|}{ Gini Ratio for SPI } & \multicolumn{3}{|c|}{$\begin{array}{l}\text { Average Human } \\
\text { Investment }\end{array}$} \\
\hline & With & Without & Changge & With & Without & Change & With & Without & $\begin{array}{c}o \\
\text { Change }\end{array}$ \\
\hline Standard Case & 0.2543 & 0.2452 & -3.6 & 0.2254 & 0.2062 & -8.5 & 0.285 & 0.539 & +89]$. \\
\hline $\begin{array}{l}\text { Additive } \\
\text { Separability }\end{array}$ & 0.2557 & 0.2466 & -3.5 & 0.2339 & 0.2141 & -8.5 & 0.293 & 0.549 & +87.4 \\
\hline $\begin{array}{l}\text { Perfect } \\
\text { Substitutability }\end{array}$ & 0.2549 & 0.2466 & -3.2 & 0.2294 & 0.1945 & -15.2 & 0.292 & 0.542 & +85.6 \\
\hline$\gamma=0.5$ & 0.2482 & 0.2357 & -5.0 & 0.2272 & 0.2050 & -9.8 & 0.265 & 0.577 & +117.7 \\
\hline$y=2.5$ & 0.2575 & 0.2501 & -2.9 & 0.2321 & 0.2127 & -8.3 & 0.288 & 0.524 & +81.9 \\
\hline $45 \%-6 \%$ & 0.2544 & 0.2449 & -3.8 & 0.2262 & 0.2057 & -9.1 & 0.276 & 0.542 & +96.4 \\
\hline $75 \%-15 \%$ & 0.2512 & 0.2430 & -3.3 & 0.2230 & 0.2061 & -7.6 & 0.297 & 0.536 & +80.5 \\
\hline
\end{tabular}


FoOTiOHES

Irhe mariage decision does rot enter this modnl. So when I une the wrod "individual" or "agent", I refer to a fanily wit.

${ }^{2}$ Almost all of the life-cycle resounce allocation molels assum that the boguest. at death is the only way of transferring non-human weeth from generation to generation. Only Ishikewa (1974) and Dxagh (1978) deal with the model in wich: more than one mothod of weanth transfers ane introduced.

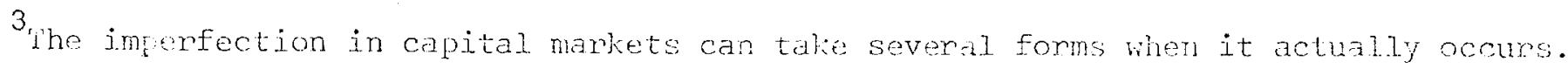
In this study, I limit my attention to onty ond form of such imperfection - Linit to one's borrowing ability.

${ }^{4}$ In contrast, nothing has been assumed as to how w is related to the charductorictics of the agent's parents. Though it is vory probable that it is proportional to hjs parent's stock of human or non-human wealth or sone other characteristics, it is assumed purely exogenous in this study.

5 The sign of $\varepsilon_{12}$ is not posited here. It tums out that its sifn does not matton in the determination of the sign of the derivative $\frac{d}{d q^{\prime}}$ wich we ane most interosted in.

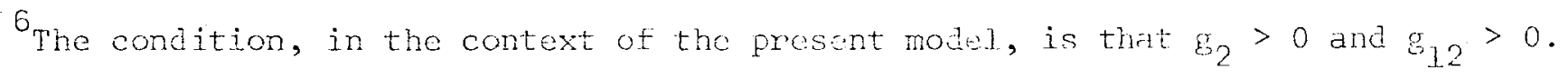
7 One period of an individual's econonic life is assumed to bo of length of 30 years. Therefoxe, assuming that he stant: lis economic life when he is lo years of age, what we call the first period in this study means the time span till the age of 40 , and the second period is thereafter untiz the age of 70 . An individual. who is 10 years old may not be mature enough to plan his ow economic life. But that age is 
${ }^{7}$ (cont'd) selected to avoid the awkward case where an individual with more human investment has a higher wage earnings even during the first period, contrary to what the theoretical model implies. This can happen if the first period of the model is set to include a later stage of one's calendar age because of the steep wage profile of high education receivers.

8 Annual wage earnings are discounted by the rate of $(r-g)$, where $r$ and $g$ denote real
the interest rate and the growth rate of the economy respectively. The reason why $(r-g)$, instead of $r$, is used as the rate of discount is that cross-section data are used here. If all of the wage rates grew by the rate of $g$, discounting by the rate of $(r-g)$ would be an appropriate procedure for cross-section data. A value of $1.5 \%$ per annum is chosen for the rate of discount assuming that $r$ and $g$ are $3 \%$ and $1.5 \%$ respectively.

9 Since economic age zero in this model corresponds to calendar age 10, the average stock of initial human capital is assumed to be 5 years of schooling equivalents. ${ }^{10}$ Consider a positive variate $X$ such that $Y=\log X$ is normally distributed with mean $\mu$ and variance $\sigma^{2}$. The mean $\alpha$ and variance $\beta^{2}$ of the variate $x$ are related to $\mu$ and $\sigma^{2}$ in the following way.

$$
\begin{aligned}
& \text { (i) } \alpha=e^{\mu+\frac{1}{2} \sigma^{2}} \\
& \text { (ii) } \beta^{2}=e^{2 \mu+\sigma^{2}}\left(e^{\sigma^{2}}-1\right)
\end{aligned}
$$

Since $c$ and $\beta$ are assumed to be 280 thousand and 114.7 thousand respectively, the mean of a log-normal distribution, $\mu$, is set to 5.5572 while the standard deviation $\sigma$, is set to 0.3939 .

${ }^{1}$ Compare with Blinder's (1974) ratio of 0.258 . 
${ }^{12}$ For discussion of the drawbacks of the data, see Blinder (1974, pp. 91-93). ${ }^{13}$ Due to inflation, a dollar in 1960, when the survey was taken, is worth only 48. 8 \% in 1977.

${ }^{14}$ These percentages are slightly higher than what the original survey data show. I suspect there was a fairly substantial. understatement of inherjtances received among respondents.

${ }^{15}$ See, for example, Driffill (1977).

${ }^{16}$ Most of the estimates of the income elasticity of labor supply, from which the income elasticity of leisure consumption can be derived, lie in the region 0.000 and -0.160. See Killingsworth (1976). However, it does not seem that a consensus is reached about the issue.

17 This case corresponds to Blinder's (1974) "Egalitarian Society" except for one thing - his egalitarian society assumes that the correlation between $w_{0}$ and I is zero while my case assumes it to be 0.12 .

18 see, for example, Mincer (1974).

19

The constant $c$ is assumed to be distributed nomally with the mean of 1.0 and the standard deviation of 0.2 to introduce some randomness in the determination of $\mathrm{w}_{2}$

20 The lifetime potential income defined as such is greater than the sum of labor earnings and capital income by th: discounted sum of intergenerational transfers received. Also note that the imputed value of the government expenditures is not included in the definition. This omission would not pose a serious problem since the changes in tax revenues, and therefore the government expenditures, are not that great. 
2IThe second period income (SPI) is defined by the sum of labor earnings, that is, $w_{1} \cdot g \cdot\left(1-\varepsilon_{2}\right)$, and interest income. The simulation results show that those who increase human investment following the elimination of the borrowing limit, mostly the lower and middle income classes, significantly decrease leisure consumption $\left(n_{2}\right)$, while the rich do not change their leisure consumption. This might be responsible for such a difference between the degrees of improvement in the distributions of LPI and SPI. The other factor is that, due to discounting, the increase in the second period labor income due to increased human investment increases the lifetime potential income by a much smaller amount. ${ }^{22}$ Note that this figure is an overestimation of the true increase in national income for the following two reasons. First, such a general increase in human investment reduces labor supply by younger workers. Hence the value of reduced labor supply during the first period should be subtracted from the above figure to reach a true increase in national income for the whole population. Second, due to general equilibrium effects, such an increase in the aggregate labor supply, measured in efficiency units, would depress the overall wage rates: ${ }^{23}$ Atkinson (1970), points out that, even though the condition that the Lorenz curves do not intersect holds, the Gini ratio still embodies some specifie social welfare function.

${ }^{24}$ See Pryor (1973) for simulation of income distribution in a multi-generation setting.

${ }^{25}$ Note that this conversion also depends on the chosen value for $\alpha$, elasticity of the marginal utility of consumption.

26 The Gini ratio for $A_{0}$ in this case is 0.8645 as opposed to 0.8051 of the standard case.

27 The Gini ratio for $A_{0}$ in this case is 0.7197 , the lowest of the three cases. 
${ }^{28}$ It should be noted, however, that this may not hold in a general equilibrium setting.

29 The assumptions are:

(S.l) $\quad \mathrm{U}_{33} \mathrm{~g}_{11} \mathrm{~h}_{2} \cdot-\mathrm{w}_{1} \mathrm{~B}_{2}\left(\mathrm{~g}_{1}\right)^{2} \geqq 0$

(S.2) $\quad B_{11}-g_{1} h_{2} B_{12} \leqq 0$

(S.3) $\quad B_{12}-g_{1} h_{2} B_{22} \gg 0$.

These conditions are assumed to hold everywhere, not necessarily in the neighborhood of equilibrium. For limit in space, I omit the discussion of their implications. 


\section{REFERENCES}

A.B. Atkinson, "On the Measurement of Inequality," Journal of Economic Theory, September 1970, 2, pp. 244-263.

, "Captial Taxes, the Redistribution of Wealth and Individual Savings," Peview of Economic Studies, April 1971, 38, pp. 209-228.

, "The Distribution of Wealth and the Individual Life-Cycle," Oxford Economic Papers, July 1971, 23, pp. 239-254.

G.S. Becker, Human Capital, revised edition, New York: National Bureau of Economic Research, 1975 .

and N. Tomes, "An Equilibrium Theory of the Distribution of Income and Intergenerational Mobility," Jounnal of Political Economy, December 1979, 87, Pp. $1153-1189$.

A.S. Blinder, Toward an Econom ic Theory of Income Distribution, Cambridge, Mass.: MIT Press, 1974.

, "Intergenerational Transfers and Life Cycle Consumption," American Economic Review, May 1976, 66, pp. 87-93.

and $Y$. Weiss, "Human Capital and Labor Supply: A Synthesis," Journal of Political Economy, June 1976, 84, pp. 449-472.

G. Cooper, A Voluntary Tax? New Perspectives on Sophisticated Estate Tax Avoidance, Washington, D.C.: Brookings Institution, 1979.

A. Drazen, "Government Debt, Human Capital and Bequests in a Life-Cycle Model," Journal of Political Economy, June 1978, 86, pp. 505-516.

E. Driffill, "Essays in Human Capital Accumulation and Labor Supply," Ph.D. dissertation, Princeton University, 1977.

J. Eaton and H.S. Rosen, "Taxation, Human Capital and Uncertainty," American Economic Review, September 1980, 90, pp. 705-715.

J.S. Flemming, "The Utility of Wealth and the Utility of Windfalls," Review of Economic Studies, January 1969, 36, pp. 55-56.

J.J. Heckman, "A Life Cycle Model of Earnings, Learning and Consumption," Journal of Political Economy, August 1976, 84, pp. 511-544.

T. Ishikawa, "Imperfection in the Capital Market and the Institutional Arrangement of Inheritance," Review of Economic Studies, July 1974, 41, pp. 383-404.

M.R. Killingsworth, "Neoclassical Labor Supply Models: A Survey of Recent Literature on Determinants of the Supply of Time to the Labor Market," mimeo, 1976.

E. Lazear, "Education: Consumption or Production?" Journal of Political Economy, June 1977, 85, pp. 569-597.

D. Levhari and Y. Weiss, "The Effect of Risk on the Investment in Human Capital," American Economic Review, December 1974, 64, pp. 950-963. 
J. Mincer, "Investrient in Human Capital and Personal. Income Distribution," Journal of Political Economy, August, 1953, 66, pp. 281-302. , Schooling, Experiencs and Eamnings, New York: National Bureau of Economic Research, 1974.

G. Orcutt and et.al., Policy Exploration through Microanalytic Simulation, Washington, D.C.: Unban Institute, 1970.

J.A. Pechman and B.A. Okner, who Bears the Tax Burden? Washington, D.C.: Brookings Institution, 1974 .

F.L. Pryor, "Simulation of the Impact of Social and Economic Institutions on the Size Distribution of Income and Wealth," American Economic Review, March 1973, 63 , pp. 50-72.

G.S. Sahota, "Theories of Personal Income Distribution: A Survey," Journal of Economic Literature, March 1978, 16, pp. 1-55.

P.A. Samuelson, "An Exact Consumption-Loan Model of Interest with or without the Social Contrivance of Money," Journal of Political Economy, December 1958, 66, pp. $462-487$.

M.E. Yaari, "On the Consumer's Lifetime Allocation Process," International Economic Review, September 1964, 5, pp. 304-31.7. 